\title{
Database Quality Plan
}

National Cancer Institute

\section{Source}

National Cancer Institute. Database Quality Plan. NCI Thesaurus. Code C115757.

A proposed method to define procedures for the creation and implementation of a quality control (QC) plan. 